\title{
Post-feeding Changes in Distribution of Free Amino Acids and Ammonia in Plasma and Erythrocytes of Carp*1
}

\author{
Hiroshi OGata*2
}

(Accepted March 27, 1985)

\begin{abstract}
Distributions of free amino acids and ammonia in plasma and erythrocytes of carp Cyprinus carpio after feeding of a casein-gelatin diet were examined to clarify physiological role of the erythrocytes in inter-organ transport of amino acids. Postprandial changes in contents of arginine, lysine, and methionine in the plasma were highly correlated to those in the whole blood, while those in the erythrocytes were not. Even when these contents in the erythrocytes reached to the maximum values, these were still less than $10 \%$ of the whole blood. Highly significant correlations were detected between levels in the whole blood and plasma or erythrocytes on the following amino acids: isoleucine, leucine, tyrosine, phenylalanine, tryptophan, and histidine. At the peak levels, contents of tyrosine, phenylalanine, and tryptophan in the erythrocytes represented approximately $40 \%$ of the respective values in the whole blood. Change of ammonia content in the whole blood was more highly correlated to that in the erythrocytes than that in the plasma. The erythrocyte ammonia content expressed as a percentage of the whole blood content rose from 45 to $85 \%$ in accordance with the increment in the whole blood ammonia content. These results indicate presence of three types of inter-organ transport of free amino acids in carp.
\end{abstract}

Previously, we have reported characteristic distributions of free amino acids (FAA) and related compounds in the plasma and erythrocytes on four freshwater fishes. ${ }^{1)}$ A physiological role of erythrocytes in inter-organ transport of FAA can be also expected in fishes as have been emphasized in higher vertebrates. ${ }^{2-8)}$ Recently, DABrowsKI suggested the presence of three different interorgan transporting systems of FAA in the blood of carp Cyprinus carpio based on the postprandial changes of FAA in the plasma and erythrocytes. ${ }^{10)}$ However, he examined the postprandial changes at only four intervals, 3, 6, 24, and $72 \mathrm{~h}$, after feeding. Since remarkable changes in the plasma FAA levels have been known to occur within $12 \mathrm{~h}$ after the consumption of a casein diet, ${ }^{11,12)}$ more frequent examination should be performed to explain sufficiently the erythrocytes role in interorgan transport of FAA. Therefore, FAA distributions between plasma and erythrocytes of carp after feeding of a casein-gelatin diet were studied to elucidate physiological role of the erythrocytes in inter-organ transport of FAA in more detail.

\section{Materials and Methods}

Composition of the experimental diet having the mixture of casein and gelatin $(5: 2, w / w)$ as a protein source was the same as that previously reported by Murai et al..$^{13)}$ Protein level of the dry diet was $33 \%$ and the essential amino acid composition per $100 \mathrm{~g}$ of dry diet was as follows: arginine, $1.63 \mathrm{~g}$; histidine, $0.75 \mathrm{~g}$; isoleucine, 1.27 $\mathrm{g}$; leucine, $2.40 \mathrm{~g}$; lysine, $1.96 \mathrm{~g}$; methionine, $0.70 \mathrm{~g}$; cystine, $0.38 \mathrm{~g}$; phenylalanine, $1.38 \mathrm{~g}$; tyrosine, $1.37 \mathrm{~g}$; threonine, $1.14 \mathrm{~g}$; tryptophan, $0.27 \mathrm{~g}$; and valine, $1.63 \mathrm{~g}$.

Carp, weighing approximately $60 \mathrm{~g}$, were stocked in a columnar polyvinyl chloride tank $(\phi 42 \times 80 \mathrm{~cm})$ and acclimatized to the experimental condition. Water temperature was controlled at $25.0 \pm 0.5^{\circ} \mathrm{C}$ by a constant addition of preheated well water during the experiment. Fish were fed the diet once a day at 9:00 a.m. at a level of $3 \%$ of body weight for one week. At $48 \mathrm{~h}$ after final feeding, blood samples for zero time were taken. The remaining fish were fed the experimental diet in a similar manner to the preliminary feeding, and then duplicate blood samples were taken

*1 Part of this paper was presented at the annual meeting of the Japanese Society of Scientific Fisheries, Kyoto, Japan, October, 1983.

*2 Inland Station, National Research Institute of Aquaculture, Tamaki, Mie 519-04, Japan (尾形 博: 農林水産省殖研究所). 
Table 1. Postprandial levels of free amino acids in the plasma of carp ( $\mu$ mole $/ l$ of whole blood)

\begin{tabular}{|c|c|c|c|c|c|c|c|c|}
\hline \multirow{2}{*}{ Amino acids } & \multicolumn{8}{|c|}{ Hours after feeding } \\
\hline & Start & 1 & 2 & 4 & 6 & 8 & 12 & 24 \\
\hline Taurine & $312(24)$ & $304(136)$ & $368(43)$ & $380(49)$ & $417(151)$ & $491(51)$ & $374(12)$ & $325(7)$ \\
\hline Aspartic acid & $18(20)$ & $5(1)$ & $6(1)$ & $154(1)$ & $6(4)$ & $5(3)$ & $54(69)$ & $36(45)$ \\
\hline Threonine & $92(41)$ & $178(37)$ & $313 i$ & $410(23)$ & $523(29)$ & $468(162)$ & $269(32)$ & $190(35)$ \\
\hline Serine & $65(28)$ & $122(50)$ & $223(59)$ & $404(5)$ & $570(89)$ & $626(167)$ & $329(43)$ & $165(20)$ \\
\hline Glutamic acid & n.d. & $10(14)$ & $53(6)$ & n.d. & $54(18)$ & $70(5)$ & $16(22)$ & $30(2)$ \\
\hline Glutamine & $237(56)$ & $299(88)$ & $493(107)$ & $818(63)$ & $608(146)$ & $544(106)$ & $498(5)$ & $267(46)$ \\
\hline Glycine & $261(97)$ & $224(85)$ & $178(59)$ & $362(67)$ & $771(66)$ & $1105(276)$ & $728(71)$ & $416(21)$ \\
\hline Alanine & $251(74)$ & $246(70)$ & $406(93)$ & $707(54)$ & 1068 ( 259) & $807(358)$ & $378(15)$ & $341(83)$ \\
\hline Valine & $148(31)$ & $215(15)$ & $319(24)$ & $449(31)$ & $402(78)$ & $317(39)$ & $330(53)$ & $150(18)$ \\
\hline Methionine & $28(6)$ & $92(6)$ & $158(14)$ & $149(10)$ & $104 \quad(11)$ & $62(14)$ & $56(7)$ & $43(0)$ \\
\hline Isoleucine & $69(17)$ & $108(15)$ & $177(7)$ & $267(26)$ & $238(50)$ & $156(26)$ & $164(28)$ & $66(2)$ \\
\hline Leucine & $147(32)$ & $402(45)$ & $545(49)$ & $511(104)$ & $308(144)$ & $213(44)$ & $244(30)$ & $125(2)$ \\
\hline Tyrosine & $27(7)$ & $157(5)$ & $257(43)$ & $188(21)$ & $196(15)$ & $152(9)$ & $89(21)$ & $89(20)$ \\
\hline Phenylalanine & $37(9)$ & $176(3)$ & $289(9)$ & $258(25)$ & $187(7)$ & $130(5)$ & $89(13)$ & $78(19)$ \\
\hline Ammonia & $199(27)$ & $245(43)$ & $476(38)$ & $582(55)$ & $359(47)$ & $264(2)$ & $177(76)$ & $204(33)$ \\
\hline Tryptophan & $7(1)$ & $38(4)$ & $33(5)$ & $20(2)$ & $10(2)$ & $13(5)$ & $13(3)$ & $15(6)$ \\
\hline Lysine & $250(48)$ & $446(102)$ & $689(106)$ & $720(53)$ & $571(77)$ & $487(160)$ & $397(34)$ & $349(67)$ \\
\hline Histidine & $131(42)$ & $205(12)$ & $296(19)$ & $238(12)$ & $152(33)$ & $189(13)$ & $152(31)$ & $174(28)$ \\
\hline Arginine & $66(8)$ & $320(8)$ & $361(67)$ & $272(21)$ & $203(36)$ & $202(68)$ & $155(10)$ & $121(6)$ \\
\hline Hydroxyproline & $198(73)$ & $221(8)$ & $132(83)$ & $186(28)$ & $347(90)$ & $817(125)$ & $816(132)$ & $463(221)$ \\
\hline Proline & $2051(826)$ & $1471(759)$ & $698(192)$ & $1523(529)$ & $2843(501)$ & $5039(1727)$ & $3787(417)$ & $3298(869)$ \\
\hline$\Sigma \mathrm{EAA}$ & $1000(243)$ & $2336(286)$ & $3441(320)$ & $3484(134)$ & $2898(438)$ & $2396(515)$ & $1961(123)$ & $1401(28)$ \\
\hline$\Sigma$ NAA & $3079(1185)$ & $2597(1043)$ & $2189(591)$ & $4152(744)$ & $5966(584)$ & $9013(2483)$ & $6605(981)$ & $5016(1050)$ \\
\hline$\Sigma \mathrm{NRS}$ & $4591(1452)$ & $5481(1505)$ & $6474(915)$ & $8599(605)$ & $9940(1219)$ & $12164(2950)$ & $9118(1181)$ & $6947(982)$ \\
\hline
\end{tabular}

All values represent the mean of two samples. The values in the parenthese are standard deviations.

EAA: essential amino acids. NAA: nonessential amino acids. NRS: ninbydrin reacting substances. n.d.: not detected. 
Table 2. Postprandial levels of free amino acids in the erthrocytes of carp ( $\mu$ mole/ $l$ of whole blood)

\begin{tabular}{|c|c|c|c|c|c|c|c|c|}
\hline \multirow{2}{*}{ Amino acids } & \multicolumn{8}{|c|}{ Hours after feeding } \\
\hline & Start & 1 & 2 & 4 & 6 & 8 & 12 & 24 \\
\hline Taurine & $7370(311)$ & $6932(236)$ & $6824(46)$ & $7048(337)$ & $6603(106)$ & $6968(112)$ & $6899(272)$ & $6757(600)$ \\
\hline Aspartic acid & $58(14)$ & $81(16)$ & $73(13)$ & n.c. & $36(3)$ & $55(2)$ & $12(17)$ & $29(41)$ \\
\hline Threonine & $131(15)$ & $190(6)$ & $231(17)$ & $205(18)$ & $194(22)$ & $205(11)$ & $145(6)$ & $226(5)$ \\
\hline Serine & $125(15)$ & $117(22)$ & $143(32)$ & $223(20)$ & $231(34)$ & $295(62)$ & $198(27)$ & $238(51)$ \\
\hline Glutamic acid & $119(14)$ & $127(11)$ & $110(11)$ & $154(12)$ & $126(6)$ & $159(5)$ & $142(3)$ & $167(1)$ \\
\hline Glutamine & $363(72)$ & $263(10)$ & $285(13)$ & $382(4)$ & $271(68)$ & $252(80)$ & $245(67)$ & $331(93)$ \\
\hline Glycine & $449(11)$ & $323(140)$ & $273(14)$ & $331(14)$ & $306(75)$ & $456(74)$ & $274(766)$ & $493(108)$ \\
\hline Alanine & $359(19)$ & $272(9)$ & $312(5)$ & $387(25)$ & $404(91)$ & $443(37)$ & $319(26)$ & $428(24)$ \\
\hline Valine & $81(10)$ & $98(3)$ & $136(20)$ & $160(25)$ & $129(17)$ & $110(49)$ & $133(25)$ & $128(7)$ \\
\hline Methionine & $18(2)$ & 12( & $17(2)$ & $61(9)$ & $27(11)$ & $9(3)$ & $24(3)$ & 27( \\
\hline Isoleucine & $40(6)$ & 38( & $60(4)$ & $94(13)$ & $83(23)$ & $62(6)$ & $61(17)$ & $47(13)$ \\
\hline Leucine & $79(11)$ & $123(9)$ & $193(6)$ & $221(48)$ & $137(66)$ & $95(8)$ & $95(21)$ & $88(26)$ \\
\hline Tyrosine & $26(4)$ & $177(3)$ & $187(36)$ & $145(18)$ & $115(6)$ & $91(15)$ & $52(18)$ & $68(3)$ \\
\hline Phenylalanine & $14(9)$ & $120(10)$ & $203(11)$ & $189(25)$ & $110(5)$ & $78(14)$ & $56(9)$ & $60(0)$ \\
\hline Ammonia & $170(14)$ & $229(24)$ & $366(40)$ & $1021(13)$ & $823(19)$ & $780(130)$ & $894(79)$ & $934(74)$ \\
\hline Tryptophan & $13(2)$ & $26(9)$ & $32(5)$ & $19(4)$ & $9(2)$ & $6(6)$ & $12(4)$ & $18(4)$ \\
\hline Lysine & $46(9)$ & $58(43)$ & $66(12)$ & $96(14)$ & $66(20)$ & $70(35)$ & $99(13)$ & $184(65)$ \\
\hline Histidine & $61(12)$ & $80(10)$ & $102(11)$ & $103(8)$ & $82(11)$ & $74(3)$ & $68(27)$ & $85(25)$ \\
\hline Arginine & $18(15)$ & $5(8)$ & $21(11)$ & $46(3)$ & $35(2)$ & $24(17)$ & $48(17)$ & $80(36)$ \\
\hline Hydroxyproline & $148(10)$ & $194(31)$ & $123(50)$ & $133(8)$ & $112(25)$ & $139(36)$ & $120(89)$ & $208(134)$ \\
\hline Proline & $1112(628)$ & $1398(132)$ & $978(117)$ & $1142(207)$ & $1154(317)$ & $1499(84)$ & 1055 ( 224) & $1734(845)$ \\
\hline$\Sigma$ EAA & $531(67)$ & $866(49)$ & $1248(49)$ & 1337 ( 167$)$ & $987(167)$ & $824(158)$ & $791(81)$ & $1014(180)$ \\
\hline$\Sigma$ NAA & $2732(504)$ & 2775 ( 294) & $2297(199)$ & $2751(133)$ & $2640(519)$ & 3298 ( 339$)$ & $2364(489)$ & $3628(1144)$ \\
\hline$\Sigma \mathrm{NRS}$ & $10803(896)$ & $10801(15)$ & $10735(25)$ & $12156(315)$ & $11052(773)$ & $11870(257)$ & $10948(920)$ & $12332(651)$ \\
\hline
\end{tabular}

Free amino acid contents in the erythrocytes were calculated from the whole blood and the plasma contents with the correction by bematocrit values according to the equation of HAGENFELDT
and ARVIDSSON.14) and ARVIDSSON. ${ }^{14}$

See Table 1.

n.c.: not calculated. 
individually from the caudal vein-artery complex with heparinized syringe under anesthesia with $0.01 \%$ solution of MS-222 at $1,2,4,6,8,12$, and $24 \mathrm{~h}$ after feeding. Sample preparation for FAA analyses of the plasma and whole blood was carried out by the same method as that reported previously. ${ }^{1)}$ FAA contents in the erythrocytes were calculated from the whole blood and plasma contents with correction by hematocrit values according to the equation of HAGENFELDT and ARvidSSON, ${ }^{1,14)}$ so called "calculated erythrocytes contents." FAA were determined using an automatic amino acid analyzer (Hitachi Model 835).

\section{Results}

FAA contents in the plasma and erythrocytes per litre of the whole blood are shown in Tables 1 and 2, respectively. Distributions of the erythrocytes FAA after feed intake are presented in Table 3 as a percentage of each FAA in the whole blood. Correlation coefficients of post-feeding changes in each FAA contents among the whole blood, plasma, and erythrocytes are listed in Table 4.

\section{FAA Detected Principally in Plasma}

Lysine, arginine, and methionine in the plasma exhibited typical postprandial changes, i.e. these amino acids quickly reached the maximum levels within $2-4 \mathrm{~h}$, and then decreased slowly but not to the basal levels by $24 \mathrm{~h}$. Whereas, the erythrocytes contents of these amino acids changed erratically or with the lesser extent compared with those of the plasma. Moreover, at the peak levels, these amino acids in the erythrocytes represented merely less than $10 \%$ in the whole blood. Also, changes in the plasma contents of these amino acids after feed intake were highly and positively correlated to those in the whole blood, while changes in the erythrocytes were not. Postprandial contents of threonine, glycine, glutamine, hydroxyproline, and proline in the plasma became up to 2.5-5.7 times higher than their initial values. However, these erythrocytes levels hardly showed any consistent changes after feed intake. Also, correlation coefficients of postprandial changes of these amino acids between the erythrocytes and whole blood were not statistically significant. The percentage proportions of these amino acids in the plasma against the whole blood were slightly low compared with those of arginine, lysine, and methionine, i.e. $41.3-73.0 \%$ for threonine, $39.5-$ $69.2 \%$ for glutamine, $36.8-65.2 \%$ for glycine, $51.8-87.2 \%$ for hydroxyproline, and $41.6-78.2 \%$

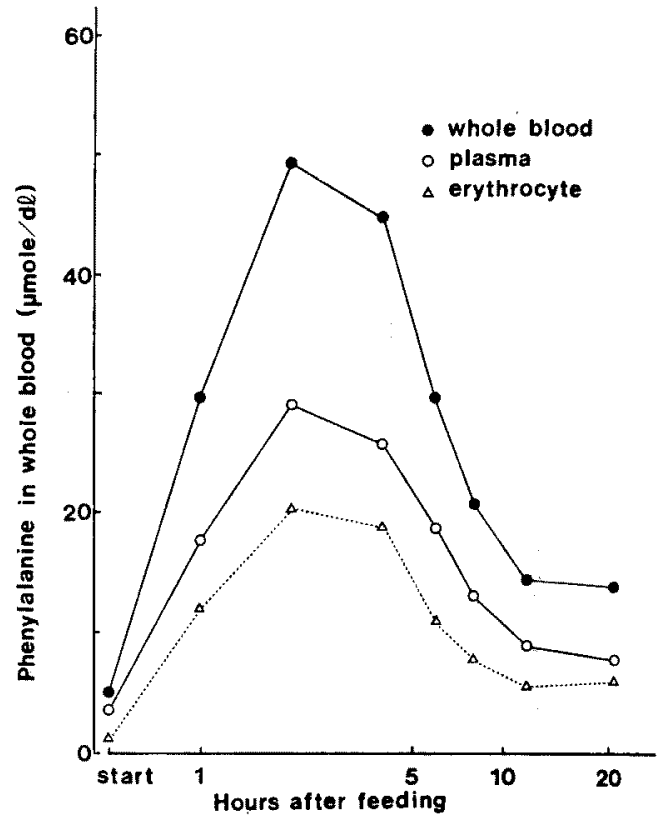

Fig. 1. Changes of phenylalanine levels in the whole blood, plasma, and erythrocytes of carp after feeding a casein-gelatin diet.

for proline.

\section{FAA Detected in Both Plasma and Erythrocytes}

Serine, alanine, valine, isoleucine, leucine, tyrosine, phenylalanine, tryptophan, and histidine, can be included in this type. These levels in both erythrocytes and plasma showed drastical postfeeding changes. Particularly, post-feeding changes of aromatic amino acids in the erythrocytes were almost the same degree as those in the plasma. The peak values of tyrosine and phenylalanine in the erythrocytes were 7.2 and 14.5 times higher than the initial values, respectively. Data for phenylalanine are shown in Fig. 1. However, percentage proportions of these amino acids in the erythrocytes became relatively lower than those in the plasma as these levels in the whole blood reaching the peaks, except phenylalanine whose proportion became larger from $27.5 \%$ of the initial value to $42.2 \%$ at the peak. Further, post-feeding changes of isoleucine, leucine, tyrosine, phenylalanine, tryptophan, and histidine in the erythrocytes were correlated highly to these whole blood changes and significantly to those in the plasma.

\section{FAA Detected Principally in Erythrocytes}

Aspartate and glutamate contents in the erythrocytes accounted for more than $60 \%$ of the 
Table 3. Free amino acid levels in the erythrocytes when expressed as a percentage of the whole blood levels $(\%)$

\begin{tabular}{|c|c|c|c|c|c|c|c|c|}
\hline \multirow{2}{*}{ Amino acids } & \multicolumn{8}{|c|}{ Hours after feeding } \\
\hline & start & 1 & 2 & 4 & 6 & 8 & 12 & 24 \\
\hline Taurine & 95.9 & 95.8 & 94.9 & 94.9 & 94.0 & 93.4 & 94.8 & 95.4 \\
\hline Aspartic acid & 77.3 & 94.2 & 92.4 & n.c. & 85.7 & 91.7 & 35.3 & 59.2 \\
\hline Threonine & 58.7 & 51.6 & 42.5 & 33.3 & 27.0 & 30.5 & 35.0 & 54.5 \\
\hline Serine & 65.8 & 49.2 & 39.1 & 35.6 & 28.8 & 32.0 & 37.6 & 59.1 \\
\hline Glutamic acid & 100.0 & 92.7 & 67.5 & 100.0 & 70.4 & 69.4 & 89.9 & 84.8 \\
\hline Glutamine & 60.5 & 46.8 & 36.6 & 31.8 & 30.8 & 31.7 & 33.0 & 55.4 \\
\hline Glycine & 63.2 & 57.5 & 35.1 & 47.8 & 34.8 & 57.3 & 36.9 & 54.3 \\
\hline Alanine & 58.8 & 52.5 & 43.5 & 35.4 & 27.4 & 35.4 & 45.8 & 55.6 \\
\hline Valine & 35.4 & 31.3 & 29.9 & 26.3 & 24.3 & 25.8 & 28.7 & 46.2 \\
\hline Methionine & 39.1 & 11.5 & 9.7 & 29.0 & 20.6 & 12.5 & 30.0 & 39.1 \\
\hline Isoleucine & 37.0 & 26.0 & 25.2 & 26.0 & 25.9 & 28.4 & 27.2 & 41.6 \\
\hline Leucine & 35.1 & 23.4 & 26.2 & 30.2 & 30.8 & 30.8 & 28.0 & 41.3 \\
\hline Tyrosine & 50.0 & 42.7 & 42.2 & 43.5 & 37.0 & 37.4 & 36.9 & 43.3 \\
\hline Phenylalanine & 27.5 & 40.5 & 41.3 & 42.2 & 37.0 & 37.5 & 38.9 & 43.5 \\
\hline Ammonia & 46.1 & 48.3 & 43.4 & 63.7 & 69.6 & 74.7 & 83.5 & 82.1 \\
\hline Tryptophan & 65.0 & 40.6 & 49.2 & 48.7 & 45.0 & 31.6 & 48.0 & 54.5 \\
\hline Lysine & 15.5 & 11.5 & 8.7 & 11.8 & 10.4 & 12.6 & 20.0 & 34.5 \\
\hline Histidine & 31.9 & 28.2 & 25.6 & 30.2 & 35.0 & 28.1 & 30.9 & 32.8 \\
\hline Arginine & 21.4 & 1.5 & 5.5 & 14.5 & 14.7 & 10.6 & 23.8 & 40.0 \\
\hline Hydroxyproline & 42.8 & 46.7 & 48.2 & 41.7 & 24.4 & 14.5 & 12.8 & 31.0 \\
\hline Proline & 35.1 & 48.7 & 58.4 & 42.9 & 28.9 & 22.9 & 21.8 & 34.5 \\
\hline IEAA & 34.7 & 27.1 & 26.6 & 27.8 & 25.4 & 25.6 & 28.8 & 42.0 \\
\hline INAA & 47.0 & 51.7 & 51.2 & 40.5 & 29.6 & 26.8 & 26.5 & 42.0 \\
\hline$\Sigma$ NRS & 70.2 & 66.3 & 62.4 & 58.9 & 52.7 & 49.4 & 54.7 & 64.0 \\
\hline
\end{tabular}

n.c.: not calculated.

whole blood contents, with exception for the values at 4 and $12 \mathrm{~h}$ of aspartate. Of glutamate, however, the whole blood exhibited a higher degree of correlation with the plasma than with the erythrocytes after feed intake. Of taurine, any consistent change was not found in the erythrocytes after feed intake, while the plasma content increased gradually but only slightly by 8 h. However, percentage proportion of taurine in the erythrocytes was above $90 \%$ of the whole blood during the experiment, and higher and more significant correlation was observed between the whole blood and the erythrocytes rather than the plasma.

In postprandial pattern of ammonia, a marked difference was found between the erythrocytes and the plasma. Changes in ammonia contents after feed intake are shown in Fig. 2. Although ammonia contents in both plasma and erythrocytes increased concomitantly by $4 \mathrm{~h}$, the plasma content decreased rapidly to the basal level by $8-12 \mathrm{~h}$, while the erythrocytes contents remained relatively higher for $24 \mathrm{~h}$. Moreover, peak value of ammonia in the erythrocytes was 6.0 times higher than the initial value, but only 2.9 times in the plasma. On a percentage distribution basis, the erythrocytes represented less than $50 \%$ of ammonia in the whole blood at the start, $63.7 \%$ at the peak, and $80 \%$ at thereafter. The postprandial change of ammonia in the erythrocytes was significantly and highly correlated only to that in the whole blood.

\section{Discussion}

Postprandial pattern of amino acid transport in the blood of carp can be principally divided to three types based on the results obtained here. The first type is the inter-organ transporting system depend mainly on the plasma in which arginine, lysine, and methionine may be involved. The second type is the one depend on both the plasma and erythrocytes. Representative amino acids in this type are tyrosine, phenylalanine, and tryptophan, whose erythrocytes contents vary in accordance with the whole blood and the plasma levels, and the erythrocytes seem to play partial role for the inter-organ transport of these amino acids. In the third type where aspartate, 
Table 4. Correlation coefficients $(\times 10)$ of postfeeding changes in each free amino acid contents among the whole blood, plasma, and erythrocytes

\begin{tabular}{|c|c|c|c|}
\hline Amino acids & $\begin{array}{l}\text { Whole } \\
\text { blood \& } \\
\text { plasma }\end{array}$ & $\begin{array}{l}\text { Whole } \\
\text { blood \& } \\
\text { ery- } \\
\text { throcytes }\end{array}$ & $\begin{array}{c}\text { Plasma \& } \\
\text { ery- } \\
\text { throcytes }\end{array}$ \\
\hline Taurine & 0.050 & $9.617^{* 4}$ & -2.794 \\
\hline Aspartic acid & -5.005 & $9.143^{* 3}$ & $-7.927^{* 1}$ \\
\hline Threonine & $9.815^{* 4}$ & 5.698 & 4.020 \\
\hline Serine & $9.899^{* 4}$ & $8.844^{* 3}$ & $8.092^{* 1}$ \\
\hline Glutamic acid & $8.018^{* 1}$ & 6.305 & 4.668 \\
\hline Glutamine & $9.672^{* 4}$ & 3.128 & 0.614 \\
\hline Glycine & $9.691^{* 4}$ & 4.027 & 1.646 \\
\hline Alanine & $9.896^{* 4}$ & $7.083^{* 1}$ & 5.996 \\
\hline Valine & $9.922^{* 4}$ & $8.164^{* 1}$ & $7.378^{* 1}$ \\
\hline Methionine & $9.677^{* 4}$ & 6.495 & 4.371 \\
\hline Isoleucine & $9.979^{* 4}$ & $9.686^{* 4}$ & $9.503^{* 4}$ \\
\hline Leucine & $9.956^{* 4}$ & $9.583^{* 4}$ & $9.274^{* 4}$ \\
\hline Tyrosine & $9.946^{* 4}$ & $9.889 * 4$ & $9.682^{* 4}$ \\
\hline Phenylalanine & $9.981^{* 4}$ & $9.967^{* 4}$ & $9.898^{* 4}$ \\
\hline Ammonia & 5.503 & $9.326^{* 4}$ & 2.118 \\
\hline Tryptophan & $9.749^{* 4}$ & $9.577^{* 4}$ & $8.701^{* 3}$ \\
\hline Lysine & $9.643^{* 4}$ & 1.179 & -1.493 \\
\hline Histidine & $9.932^{* 4}$ & $9.126^{* *}$ & $8.588 * 2$ \\
\hline Arginine & $9.743^{* 4}$ & 2.060 & -4.210 \\
\hline Hydroxyproline & $9.919^{* 4}$ & 0.106 & -1.169 \\
\hline Proline & $9.894^{* 4}$ & 5.994 & 4.768 \\
\hline
\end{tabular}

glutamate, taurine, and ammonia can be included, contribution of the erythrocytes seems to be larger than that of the plasma.

Generally, inter-organ transporting systems of FAA by means of erythrocytes are closely related to permiability across cell membrane. ${ }^{14-18)}$ We have demonstrated in four freshwater fishes that many kinds of FAA in the erythrocytes can be easily washed out by rinsing with physiological saline. ${ }^{2}$ This result indicates that amino acids in free state can pass through red blood cell membrane, by simple diffusion or active transport, as have been reported in higher vertebrates. ${ }^{14-18)}$ Further work using a radioisotope tracer technique is required for full explanation of relationship between inter-organ transport and membrane permiability of FAA in the erythrocytes of fish.

It is generally well known that ammonia is able to permiate easily and rapidly into cell across the membrane. ${ }^{10)}$ Moreover, OGATA and ARAI ${ }^{1)}$ recently demonstrated in carp, coho salmon, rainbow trout, and channel catfish that ammonia level is higher in the erythrocytes than in the plasma. These results obtained here show that

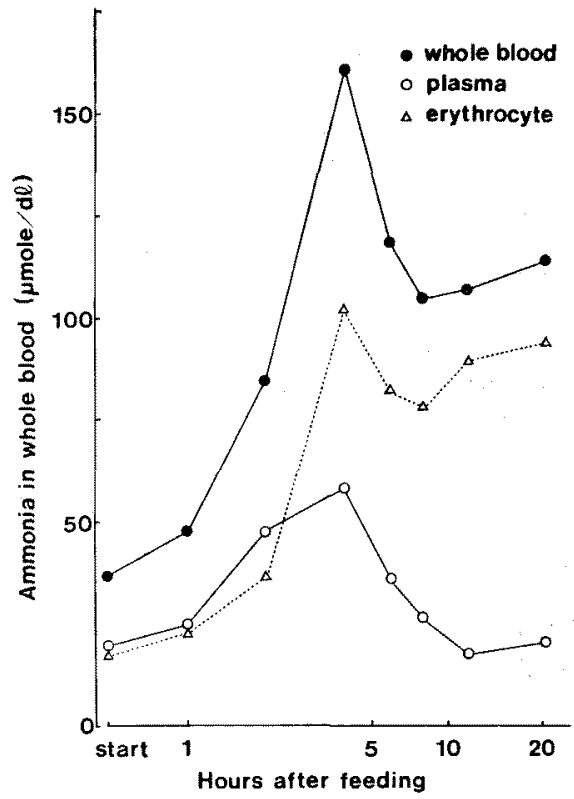

Fig. 2. Changes of ammonia levels in the whole blood, plasma, and erythrocytes of carp after feeding of a casein-gelatin diet.

inter-organ transport of ammonia derived from amino acids catabolism under the stimulus of food intake seems to depend in a greater degree on the erythrocytes. However, high erythrocyte/plasma ratio of ammonia (11.8) is also detected in rabbit* under fasting condition as have been observed in the fishes. ${ }^{1)}$ This leaned distribution of ammonia to the erythrocytes appears to be not specific for fish. The question on origin and physiological significance of ammonia occurring in the erythrocytes of carp after feed intake remains uncertain.

\section{Acknowledgments}

The author wishes to thank Mrs. T. Hirasawa and N. Ohtake and Miss. R. Yamamoto for their technical assistances. The author is also indebted to Drs. S. ARAl and T. MUral, National Research Institute of Aquaculture, for critically reviewing the manuscript.

\section{References}

1) H. Ogata and S. AraI: Bull. Japan. Soc. Sci. Fish., 51, 1181-1186 (1985).

2) R. Dawson and J. W. G. Porter: Brit. J. Nutr., 16, 27-39 (1962).

3) R. Pron: in "Protein Metabolism and Nutri-

\footnotetext{
* Unpublished data by OGATA (1984).
} 
tion" (ed. by D. J. A. Cole, K. N. Boorman, P. J. Buttery, D. Lewis, R. J. N. EALE, and H. Swan), Butterworth, London, 1976, pp. 259-277.

4) D. H. ElwyN: Fed. Proc., 25, 854-861 (1966).

5) D. H. ElWYN, W. J. Launder, H. C. Parikh, and E. M. Wise, JR.: Am. J. Physiol., 222, 1333-1342 (1972).

6) T.T. Aoki, M.F. Brennan, W.A. Muller, F.D. Moor, and G. F. CAHIL, JR.: J. Clin. Invest., 51, 2889-2894 (1972).

7) T. T. Aoki, W. A. Muller, M. F. Brennan, and G.F. CAmLL, JR.: Diabetes, 22, 768-775 (1973).

8) P. Felig, J. WAhren, and L. RaF: Proc. Natl. Acad. Sci. USA, 70, 1775-1779 (1973).

9) R. N. Hettmann and E. N. Bergman: Am. J. Physiol., 239, E242-E247 (1980).

10) K. Dabrowski: Comp. Biochem. Physiol., 72A, 753-763 (1982).

11) S. M. Plakas, T. Katayama, Y. Tanaka, and O. Deshimaru: Aquaculture, 21, 307-322 (1980).

12) T. Murai, T. Akmyama, H. Ogata, Y. Hirasawa, and T. Nose: Bull. Japan. Soc. Sci. Fish., 48, 703-710 (1982).

13) T. Murai, T. Akiyama and T. Nose: Bull. Japan. Soc. Sci. Fish., 50, 893-897 (1984).

14) L. Hagenfeldt and A. Arvidsson: Clin. Chim. Acta, 100, 133-141 (1980).

15) J. C. Waterlow, P. J. Garlick, and D. J. MILlWARD: Protein Turnover in Mammalian Tissues and in the Whole Body, Elsevier/North Holland Biochemical Press, Amsterdam, 1978, pp. 133-143.

16) G. G. Guidott, A. F. Borghetti, and G. C. Gazzola: Biochim. Biophys. Acta, 515, 329-366 (1978).

17) J. D. Young, S. E. M. Jones, and J. C. Ellory: Proc. R. Soc. London, B209, 355-375 (1980).

18) J. Lerner: Comp. Biochem. Physiol., 78A, 205215 (1984).

19) R. N. Ratnatke, J. E. Buttery, L. T. Malden, B. R. Chamberlain, and M. O'Halloran: Scand. J. Gastroenterol., 18, 103-106 (1983). 